\title{
Spatial Distribution of Internal Heat Gains: A \\ Probabilistic Representation and Evaluation of Its \\ Influence on Cooling Equipment Sizing in Large \\ Office Buildings
}

\author{
Qi Zhang ${ }^{1}$, zqi2007@sina.com \\ Da Yan ${ }^{1^{*}}$, yanda@tsinghua.edu.cn \\ Jingjing $A n^{1}$, ajj14@mails.tsinghua.edu.cn \\ Tianzhen Hong², thong@lbl.gov \\ Wei Tian³, tjtianjin@126.com \\ Kaiyu Sun², ksun@lbl.gov
}

*Corresponding author

${ }^{1}$ Building Energy Research Center, School of Architecture, Tsinghua

University, Beijing, China

${ }^{2}$ Building Technology and Urban Systems Division, Lawrence Berkeley

National Laboratory, USA

${ }^{3}$ College of Mechanical Engineering, Tianjin University of Science and

Technology, Tianjin, China

\begin{abstract}
Internal heat gains from occupants, lighting, and plug loads are significant components of the space cooling load in an office building. Internal heat gains vary with time and space. The spatial diversity is significant, even for spaces with the same function in the same building. The stochastic nature of internal heat gains makes determining the peak cooling load to size air-conditioning systems a challenge. The traditional conservative practice of considering the largest internal heat gain among spaces and applying safety factors overestimates the space cooling load, which leads to oversized air-conditioning equipment and chiller plants. In this study, a field investigation of several large office buildings in China led to the development of a new probabilistic approach that represents the spatial diversity of
\end{abstract}


the design internal heat gain of each tenant as a probability distribution function. In a large office building, a central chiller plant serves all air handling units (AHUs), with each AHU serving one or more floors of the building. Therefore, the spatial diversity should be considered differently when the peak cooling loads to size the AHUs and chillers are calculated. The proposed approach considers two different levels of internal heat gains to calculate the peak cooling loads and size the AHUs and chillers in order to avoid oversizing, improve the overall operating efficiency, and thus reduce energy use.

Keywords: internal heat gain, spatial diversity, stochastic, spatial distribution, air handling unit, equipment sizing, chiller plant

\section{Introduction}

Air-conditioning systems in large-sized commercial buildings have a central chiller plant that serves multiple air handling units (AHUs), which each serves multiple zones. The installed capacity of the chiller is commonly larger than the actual peak cooling load in order to guarantee the thermal comfort of occupants in multiple zones [1-5]. Crozier [4] monitored nine chiller plants and 16 ventilation plants in the UK and found that $100 \%$ of the chiller plants and $88 \%$ of the ventilation plants had higher capacities than the design requirements. All of the chiller plants suffered from varying degrees of excess cooling capacity; in one case, the cooling capacity was as much as four and a half times the actual maximum required capacity. The air handling equipment was significantly oversized: as much as three times the necessary fan size in some cases. Oversized chillers require bigger pumps, pipes, and cooling towers as well as a larger plant room [3]. Moreover, oversized chillers may result in a situation where some chillers are rarely operating while others are running frequently at low partial load conditions, which leads to lower efficiency and wasted energy. This oversizing is estimated to typically be responsible for an approximately 10\%-15\% increase in heating, ventilation, and air-conditioning (HVAC)-related energy consumption [4]; this also results in higher initial investment costs, larger space requirements, and higher energy consumption during operation.

Although chillers are commonly oversized, the degree of oversizing varies greatly for different buildings. Most cases have shown that oversizing is more significant in large-scale buildings with a central air-conditioning system. However, air handling equipment such as AHUs that use the same load calculation method for chiller sizing appear to be just right or undersized but not oversized [4]. Insufficient cooling often occurs with a high outdoor air temperature, strong solar radiation, or high occupancy. Analyzing the causes of this contradiction in sizing AHUs and chillers is important for proposing appropriate solutions to help HVAC engineers size chillers correctly.

Chiller oversizing can be caused by various factors. Thomas and Moller [3] pointed out several reasons such as safety factors, the space temperature setpoint, and internal heat gains that may lead to chiller oversizing. Crozier [4] considered the incorrect assessment of internal heat gains as a possible explanation for the degree of oversizing found in chiller plant surveys. Plug loads, particularly for office equipment, are generally far lower than the design values used. The uncertainty of internal heat gains is one of the most important reasons for this oversizing issue [6]. The internal heat gain density (per space floor area) is not constant and varies widely in actual buildings even with the same function [7]. For instance, in one office building, the plug load 
density was found to vary between 6 and $34 \mathrm{~W} / \mathrm{m}^{2}$ among spaces. For office buildings, differences in the number of employees, lighting, and office equipment lead to uncertainty in the internal heat gains. Moorefield et al. [8] monitored small power users in 25 offices in California over a 2-week period. If computer energy consumption is taken as an example, the electricity density would obviously vary according to different computer types (e.g., laptop or desktop computer with one display), staffs (e.g., fulltime and part-time staff), and so on. Peak cooling loads are usually calculated at the early stage of a design project when the actual internal heat gains are highly uncertain. HVAC engineers usually deal with uncertainties by assuming worst-case scenarios with a large safety factor [9]. However, worst-case scenarios rarely happen in reality. Although such a practice can meet the cooling requirements of extreme high-load areas, it will result in an oversized chiller plant.

Rules of thumb are a common practice for designers and consulting firms for building services engineering to estimate design parameters. Survey questionnaires are used to investigate the consulting firms' recommended values [10]. However, there is a large variation among the design internal heat gains used by different consulting firms. For example, the maximum internal heat gain density may be $270 \mathrm{~W} / \mathrm{m}^{2}$ while the minimum is $135 \mathrm{~W} / \mathrm{m}^{2}$, but the site measurement of the peak cooling load may be $129 \mathrm{~W} / \mathrm{m}^{2}$. Therefore, the design values for the internal heat gains recommended by the consulting firms will result in an oversized chiller.

In addition to the rules of thumb, design calculations and simulations with building performance simulation programs are also used to calculate the design cooling load of buildings. The results depend on the input values (design values and time schedules); uncertainties in the inputs would lead to uncertain results or results deviating from the true values [11, 12]. Uncertain inputs include the internal heat gain, indoor setpoint temperature, infiltration rate, and ventilation rate.

Uncertainty analysis is necessary and important for the energy analysis of buildings. Uncertainty analysis methods can be categorized into local and global sensitivity analyses. Global methods can be further subdivided into four approaches: regression, screening-based, variance-based, and meta-model sensitivity analysis [13]. Many researchers have investigated using uncertainty analysis to identify the uncertainties in the input and output of a system or simulation tool [14-16]. Tian and de Wilde [17] explored the uncertainties and sensitivities when predicting the thermal performance of buildings subjected to climate change as well as the uncertainties related to interventions in the building envelope and systems. They demonstrated their methodology on a university building in the UK. Macdonald contributed to the integration of uncertainty analysis with the Esp-r software. He quantified the effects of uncertainty in a building simulation by considering the internal temperature, annual energy consumption, and peak loads [14]. Macdonald and Strachan [18] reviewed popular uncertainty analysis methods, such as differential sensitivity analysis and Monte Carlo analysis. They applied these methods to buildings via the thermal simulation program Esp-r. Meanwhile, de Wit and Augenbroe [19] addressed uncertainties in building performance evaluations and their potential impact on design decisions and presented an approach to quantify modeling uncertainties. Hopfe and Hensen [20] simulated a realistic case study by adapting the uncertainty analyses of three different groups of uncertainty (i.e., physical, design, and scenario uncertainties) and gave a practical example of identifying the uncertainties with a great influence in the design stage. Spitz et al. [21] selected the 10 most influential parameters of the output air temperature from 139 parameters to carry out uncertainty 
analysis; the numerical uncertainty band was then compared with experimental data. The uncertainties of internal heat gains have been considered in some studies related to the early stages of air-conditioning system design. Zhu and Jiang [26] provided a method to calculate the building loads based on the minimum and maximum internal heat gains. The actual building load varies between the two loads, so both should be considered when selecting air-conditioning equipment. Probability distribution functions have been used to describe the characteristics of internal heat gain density and provide a quantifiable and detailed research basis for cooling load simulation and calculation [27]. Domínguez-Muñoz et al. [9] utilized a mathematical representation for the uncertainty, which they characterized by assigning probability distributions to the uncertain input factors. After the uncertainties are identified and quantified, the cumulative probability of the peak load is used to formulate a design decision based on a specific safety level (guaranteed rate). Nagai and Nagata [36] introduced a statistical method combining Markov chain Monte Carlo method with the Bayesian approach to characterize the zone heat gains for peak load calculation. They used lognormal distribution to describe the daytime average internal heat gain. The above studies provide a good way of using the probability distribution function to solve the problem of choosing the internal heat gain density in the design stage.

With the growth of knowledge on the effect of building occupancy on energy uncertainties, more and more researchers regard building occupancy and behavior related to window opening and lighting as the root causes of discrepancies in internal heat gains at different times and spaces [30-32]. They have proposed the occupant movement and related occupant behavior models for the building energy simulation and stochastic analysis of HVAC systems in buildings [22-25].

Although various accurate methods have been developed to describe the uncertainties of internal heat gains (e.g., occupant, lighting, and plug loads) and other input parameters and schedules in thermal simulations, these methods are relatively complicated, time-consuming, and require the use of a simulation program. Thus, they are difficult to apply in practical engineering. The HVAC design method described in ASHRAE Handbook-Fundamentals [33] is the most commonly used in practice.

According to ASHRAE Handbook-Fundamentals, the HVAC equipment capacity is determined based on the peak cooling load calculated in the design stage, which is affected by factors in four categories: external (envelope), internal (occupant, lighting, and plug loads/appliances), infiltration (air leakage), and system (outdoor air, duct leakage, fan, and pump). The radiant time series (RTS) method, which is a simplification of the heat balance method, is often used for load calculation. In the RTS method, the cooling loads of each component for each hour are summed to determine the total cooling load for each hour. This process is repeated for multiple design months to determine the month when the peak load occurs, and the peak load is then used to size the air-conditioning system. When the cooling load is estimated for a single zone, the internal heat gains are considered by using the occupant/equipment density and proposed schedules of lighting, occupancy, and appliances. When the cooling loads are estimated for a group of spaces (e.g., for an AHU that serves multiple zones), the assembled zones must be analyzed to consider (1) the simultaneous effects taking place and (2) any diversification of heat gains from occupants, lighting, and other internal load sources. The simultaneous effects are addressed by defining a diversity factor, which is the ratio of the measured peak electrical load at equipment panels to the sum of the maximum electrical load of each individual item of equipment. The fewer the pieces of equipment that operate simultaneously, the lower the diversity factor. 
ASHRAE research project RP-1093 derived diversity profiles for use in energy calculations [34, 35]. Those profiles were derived from available measured datasets for a variety of office buildings and indicated a range of peak weekday diversity factors for lighting of $70 \%-85 \%$ and for receptacles (appliance load) of $42 \%-89 \%$. The diversity factor reflects the uneven distribution of internal heat gains from the perspective of time. However, previous studies $[7,8]$ have found that the internal heat gains are also unevenly distributed from the perspective of space, which has not been addressed well in the calculation of the design cooling load. Therefore, we focused on the spatial distribution of internal heat gains and its influence on HVAC design in the present study.

Internal heat gains vary with time and space. For the variation with time, we adopted the traditional method of diversity factors: temporal schedules representing simultaneous effects, which are widely used in building energy standards such as ASHRAE Standard 90.1 and ASHRAE Handbook - Fundamentals. For the variation with space, we assumed that the design internal heat gains of spaces occupied by each tenant are independent and not influenced by time unless there are significant changes to space uses (e.g., due to major retrofits or renovation). We propose a probability distribution function to describe the spatial diversity of the design internal heat gain density of spaces occupied by each tenant-including the heat gain density from occupant, lighting, and plug loads - based on the investigation of a group of large-sized office buildings in Hong Kong. Based on the distribution characteristics of the internal heat gain density, we propose the guaranteed rate method as a simplified algorithm for identifying the specific values of the internal heat gain density to select chiller and air handling equipment. Because the service area and necessary guaranteed rate are different for the chiller and AHUs, the design values should be different. Finally, we present a real case used to demonstrate the accuracy of the proposed method.

\section{Technical approach}

The internal heat gains from occupants, plug loads, and lighting have spatial distribution characteristics in large-sized office buildings and significantly influence the HVAC equipment sizing. Thus, a technical approach based on a probabilistic distribution was developed to represent the spatial distribution characteristics of internal heat gains for the selection of reasonable design values.

The key steps are illustrated in Fig. 1:

(1) A field investigation was performed to study 46 tenants in seven office buildings in Hong Kong. The tenant floor area, number of employees, lighting, and plug loads were investigated to determine the variation and distribution of the space internal heat gain density. For each tenant, we calculated the area-weighted design internal heat gain densities for the occupant, lighting, and plug loads based on the occupied space. In addition, the installed capacity and actual required peak cooling load of the chillers were compared to determine the differences between the design and actual peak cooling loads.

(2) Based on the actual internal heat gain data, a probability distribution function was developed to describe the spatial distribution characteristics of internal heat gains. A large-sized office building usually has a central plant with multiple chillers serving multiple AHUs. An AHU can serve multiple spaces, while the central plant chillers serve all of the AHUs in the building. Therefore, the diversity of loads should be treated differently for the peak load and sizing calculations of the chillers and AHUs by using two different sets of probability distribution functions for the design internal heat gains. 
(3) We introduce the concept of a guaranteed rate to size the equipment. The guaranteed rate corresponds to the confidence level of the probability distribution function, which determines the design values of the internal heat gains for sizing calculations. For example, a guaranteed rate of 95\% means a 95\% probability that the selected design internal heat gains would not be exceeded. This also implies that the calculated peak cooling load/equipment capacity would meet the actual cooling needs for $95 \%$ of the time. The design internal heat gain density for different equipment sizes can be calculated at a certain guaranteed rate and with the corresponding probability distribution function. The guaranteed rate is often determined by designers and owners according to the building grade and other factors (e.g., occupant comfort is a priority).

(4) A case building (Building D) was used as an example to demonstrate the application and accuracy of the proposed method. The peak loads were calculated by using the method described in ASHRAE Handbook-Fundamentals. The chiller capacity, calculated cooling capacity, and actual peak cooling load were compared.

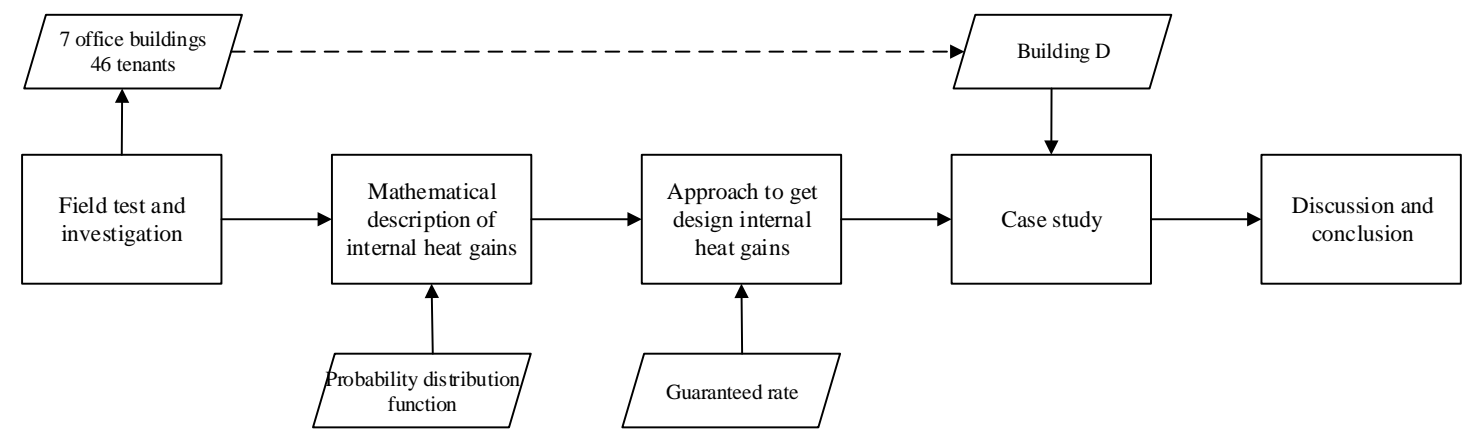

Fig. 1 Technical approach

\section{Investigation of the internal heat gain density spatial distribution}

\subsection{Investigated buildings}

Seven office buildings in Hong Kong with a gross floor area of 549,000 $\mathrm{m}^{2}$ were investigated. Error! Reference source not found. presents the building details. There were two goals: obtain the distribution of design internal heat gains and understand the gap between the installed chiller capacity and actual peak cooling loads of the buildings.

Forty-six tenants were randomly selected from the seven buildings to investigate their occupied floor area, number of employees, and lighting and plug loads for a 2-week period in the summer of 2012. We also took the hourly monitoring data of the lighting and plug loads for 1 year in 2012 from the property managers for further analysis. Two separate internal heat gain densities were considered: one calculated from the number of occupants and the metabolic rate of 134 W/person [28], and the other for the lighting and plug loads together because they were not separately monitored.

Table 1 Summary of the seven investigated office buildings in Hong Kong

\begin{tabular}{llllllll}
\hline \multicolumn{1}{c}{ Building Code } & A & B & C & D & E & F & G \\
\hline Gross Floor Area $\left(\mathrm{m}^{2}\right)$ & 62,200 & 82,400 & 44,700 & 167,500 & 64,100 & 29,500 & 98,600 \\
Number of Floors & 27 & 40 & 23 & 67 & 41 & 36 & 29 \\
$\begin{array}{l}\text { Area of a typical office floor } \\
\left(\mathrm{m}^{2}\right)\end{array}$ & 2730 & 1500 & 1440 & 2380 & 1250 & 760 & 2820 \\
Number of Investigated Tenants & 5 & 4 & 6 & 20 & 11 & 0 & 0 \\
\hline
\end{tabular}


We also investigated the installed chiller capacity based on the design specifications and the actual peak cooling loads based on the hourly monitored water flow rate and temperature difference across the chillers.

\subsection{Investigation results}

Forty-six tenants in buildings A-E were investigated to obtain the distribution of internal heat gains to determine the space design values. We chose the method used in the literature [29] for the effective detection and removal of outliers because of its simplicity. With this method, we can define data as effective values if they are larger than $Q_{1}-1.5 \times\left(Q_{3}-Q_{1}\right)$ and less than $Q_{1}+1.5 \times\left(Q_{3}-Q_{1}\right)$, where $Q_{1}$ is the lower quartile and $Q_{3}$ is the upper quartile. We eventually chose 40 tenants as effective samples for the survey. Fig. 2 shows the internal heat gain density in descending order. The differences among the samples were significant; the minimum, maximum, and average values of the total internal heat gains were 29,75 , and $46 \mathrm{~W} / \mathrm{m}^{2}$, respectively. Eighty percent of the samples ranged from 33 to $53 \mathrm{~W} / \mathrm{m}^{2}$. Various factors influence the spatial distribution characteristics of internal heat gains, such as the tenant industry (e.g., IT, sales, and banking), tenant scale (e.g., large enterprises and small businesses), and other tenant characteristics.

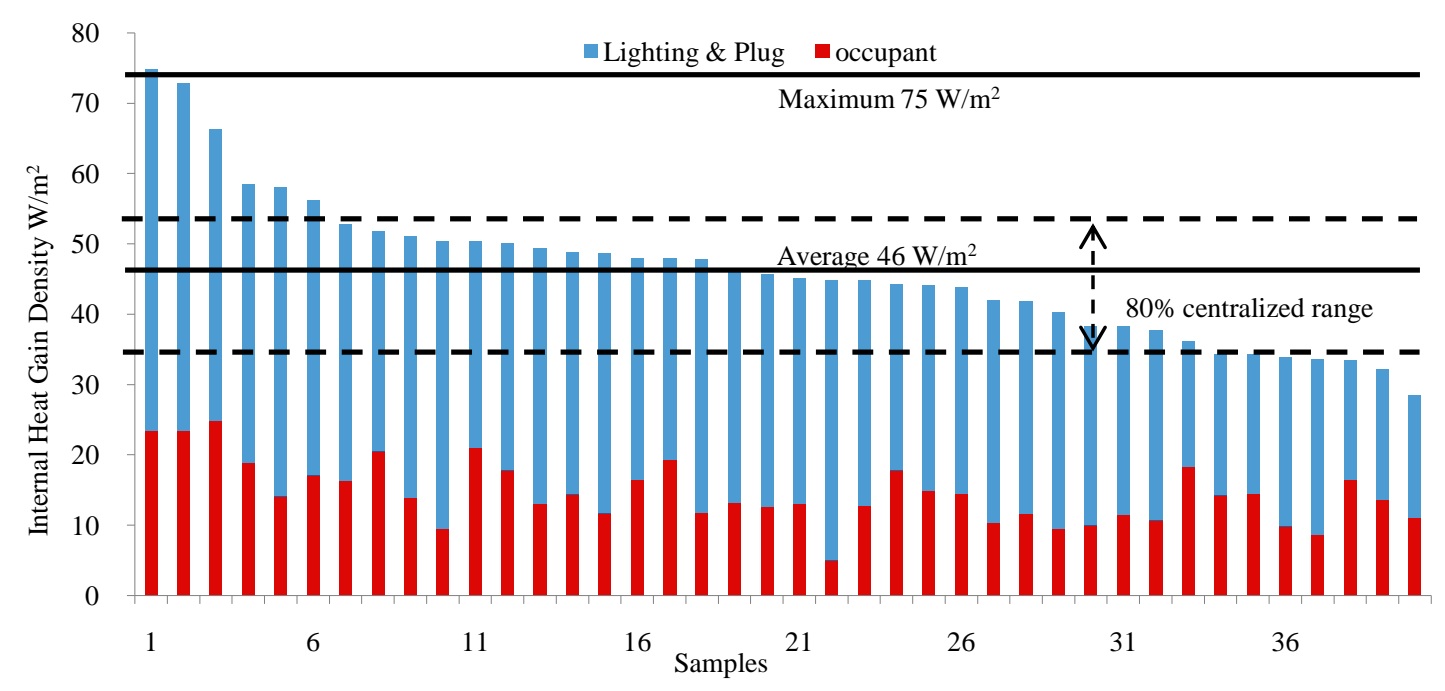

Fig. 2 Outcome of internal heat gain density survey of office buildings

Fig. 3 shows the area-weighted cumulative distribution of the investigated cases for occupants, lighting and plugs, and total internal heat gain density. Note that the floor areas of the investigated tenants were not equal; they ranged from $600 \mathrm{~m}^{2}$ to $2000 \mathrm{~m}^{2}$, and the average floor area was $1250 \mathrm{~m}^{2}$. Therefore, we considered the floor area of each tenant and calculated the cumulative probability by modifying the area of a single tenant to the gross area:

$$
F\left(X_{i}\right)=P\left(x \leq X_{i}\right)=1-P\left(x>X_{i}\right)=1-\frac{A_{1}}{\sum_{j=1}^{n} A_{j}}-\frac{A_{2}}{\sum_{j=1}^{n} A_{j}}-\cdots-\frac{A_{i-1}}{\sum_{j=1}^{n} A_{j}}
$$

Here, $X$ is the measured internal heat gain density, and the subscript $i$ represents a tenant $i=1$, $2, \ldots, n . X_{i}$ decreases with an increasing subscript number: $X_{1}>X_{2}>\cdots>X_{n} . A$ is the floor area of each tenant. For each curve, the slope was significant in the middle region compared to that at the beginning and end of the curve. This means that the internal heat gains were similar to a normal distribution. The lower and higher density values rarely appeared. 


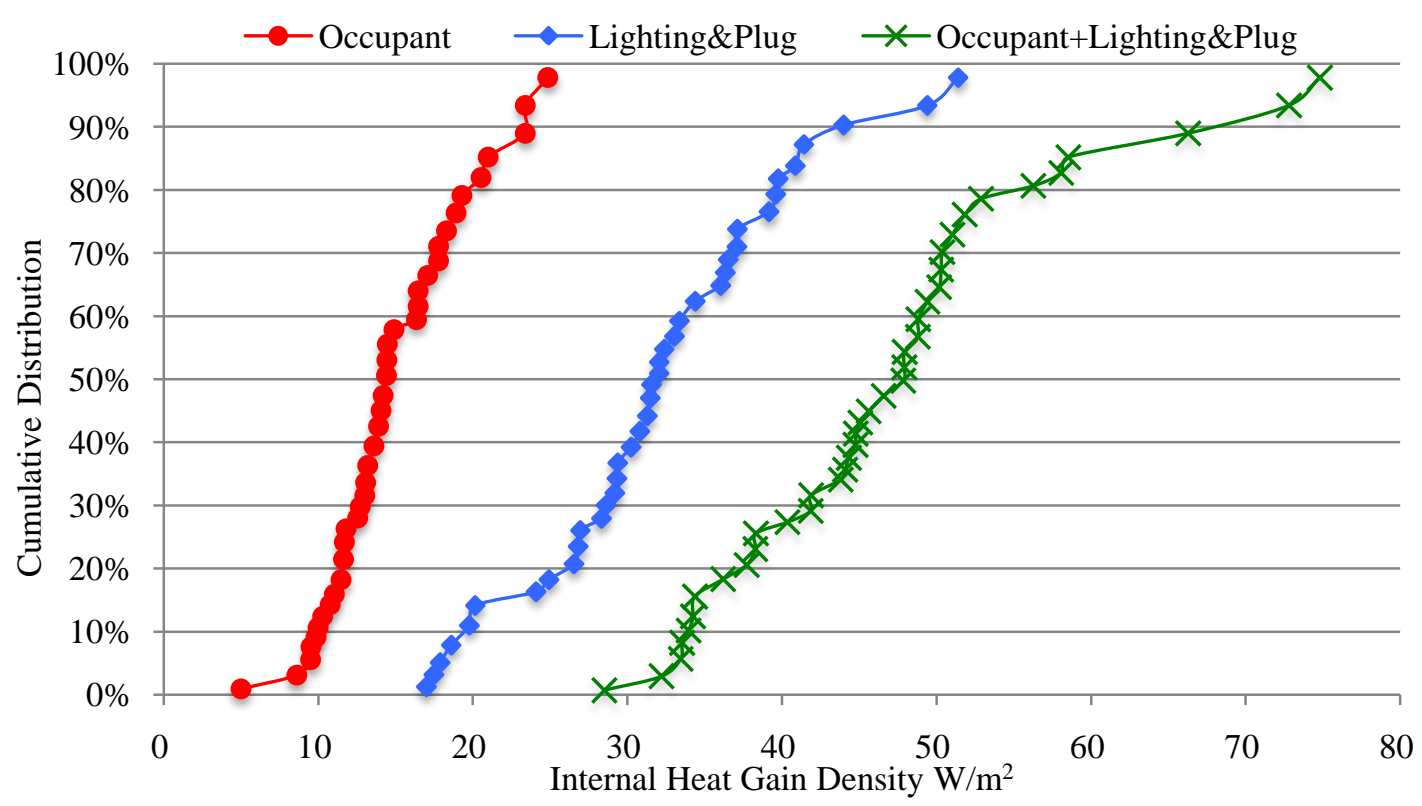

Fig. 3 Area-weighted cumulative distribution of investigated cases

In the design of air-conditioning systems or simulation of building loads, a large variation in the internal heat gain density is a difficult issue to handle with a simple deterministic approach using a fixed value, which is commonly done in the building industry. For example, using 46 $\mathrm{W} / \mathrm{m}^{2}$ as a design parameter may lead to a $50 \%$ deficiency in the air handling equipment capacity. On the other hand, using $75 \mathrm{~W} / \mathrm{m}^{2}$ as a design parameter may lead to an oversized chiller. There has to be a balance between a lack of capacity and oversized equipment.

Fig. 4 compares the actual peak cooling load and chiller capacity in several offices of buildings $\mathrm{A}-\mathrm{G}$. Buildings $\mathrm{C}-\mathrm{E}$ had individual chiller plants, while buildings $\mathrm{F}$ and $\mathrm{G}$ shared a common chiller plant. The survey results showed that chiller oversizing became more evident as the building scale increased.

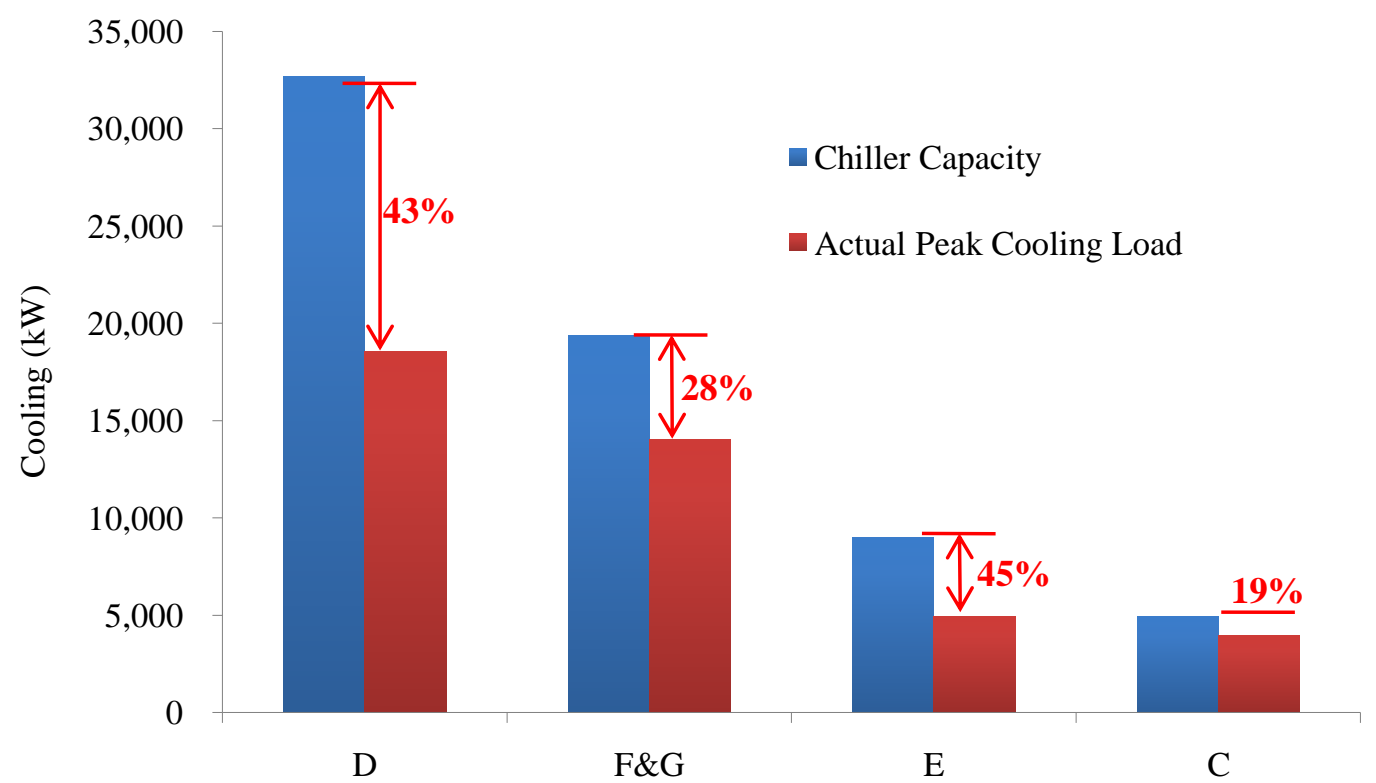

Fig. 4 Chiller capacity and actual peak cooling load in office buildings 


\section{Spatial distribution characteristics and mathematical description}

\subsection{Mathematical representation of the distribution of internal heat gains}

Based on the above survey, the spatial distribution of the internal heat gain densities was found to be significant and have an apparent impact on the building cooling loads and equipment design. In this section, we propose a normal distribution to describe the spatial distribution of internal heat gain densities based on the previous results for the seven large office buildings.

The normal distribution probability density function (PDF) is given by following function:

$$
f(x)=\frac{1}{\sqrt{2 \pi} \sigma} e^{-\frac{(x-\mu)^{2}}{2 \sigma^{2}}}
$$

Here, $\mu$ is the expected value, and $\sigma$ is the standard deviation. The normal cumulative distribution function (CDF) is the integral of the density function: $F(x)=\int_{-\infty}^{x} f(x) d x$. The expected value and standard deviation of the investigated cases can be estimated if there are sufficient data from the site survey. The area-weighted average of the investigated design internal heat gain densities is given by the function:

$$
\mu=\frac{A_{1} X_{1}+A_{2} X_{2}+\cdots+A_{n} X_{n}}{\sum_{j=1}^{n} A_{j}}
$$

The standard deviation can be calculated from the investigated cases as:

$$
\sigma=\frac{A_{1}\left(X_{1}-\mu\right)^{2}+A_{2}\left(X_{2}-\mu\right)^{2}+\cdots+A_{n}\left(X_{n}-\mu\right)^{2}}{\sum_{j=1}^{n} A_{j}}
$$

Table 2 presents the area-weighted average and standard deviation of the occupant load density, lighting and plug load density, and total internal heat gain density. The parameters are statistics obtained for an average floor area of $1250 \mathrm{~m}^{2}$.

Table 2 Expected value and standard deviation of the investigated internal heat gain densities

\begin{tabular}{cccc}
\hline & $\begin{array}{c}\text { Occupant Load Density } \\
\mathrm{W} / \mathrm{m}^{2}\end{array}$ & $\begin{array}{c}\text { Lighting \& Plug-Loads Density } \\
\mathrm{W} / \mathrm{m}^{2}\end{array}$ & $\begin{array}{c}\text { Total Internal Load Density } \\
\mathrm{W} / \mathrm{m}^{2}\end{array}$ \\
\hline $\begin{array}{c}\text { Area-weighted Average } \mu \\
\text { Area-weighted Standard Deviation }\end{array}$ & 15.4 & 32.5 & 47.9 \\
$\sigma$ & 4.7 & 8.8 & 11.6 \\
\hline
\end{tabular}

Based on the estimated expected value and standard deviation, Fig. 5 compares the corresponding normal distribution functions with observations, where the solid lines are the real cumulative distributions of the survey data. The dashed lines represent the fitting cumulative distributions with the area-weighted average and area-weighted standard deviation of the survey data. The average floor area of the investigated cases was $1250 \mathrm{~m}^{2}$. 


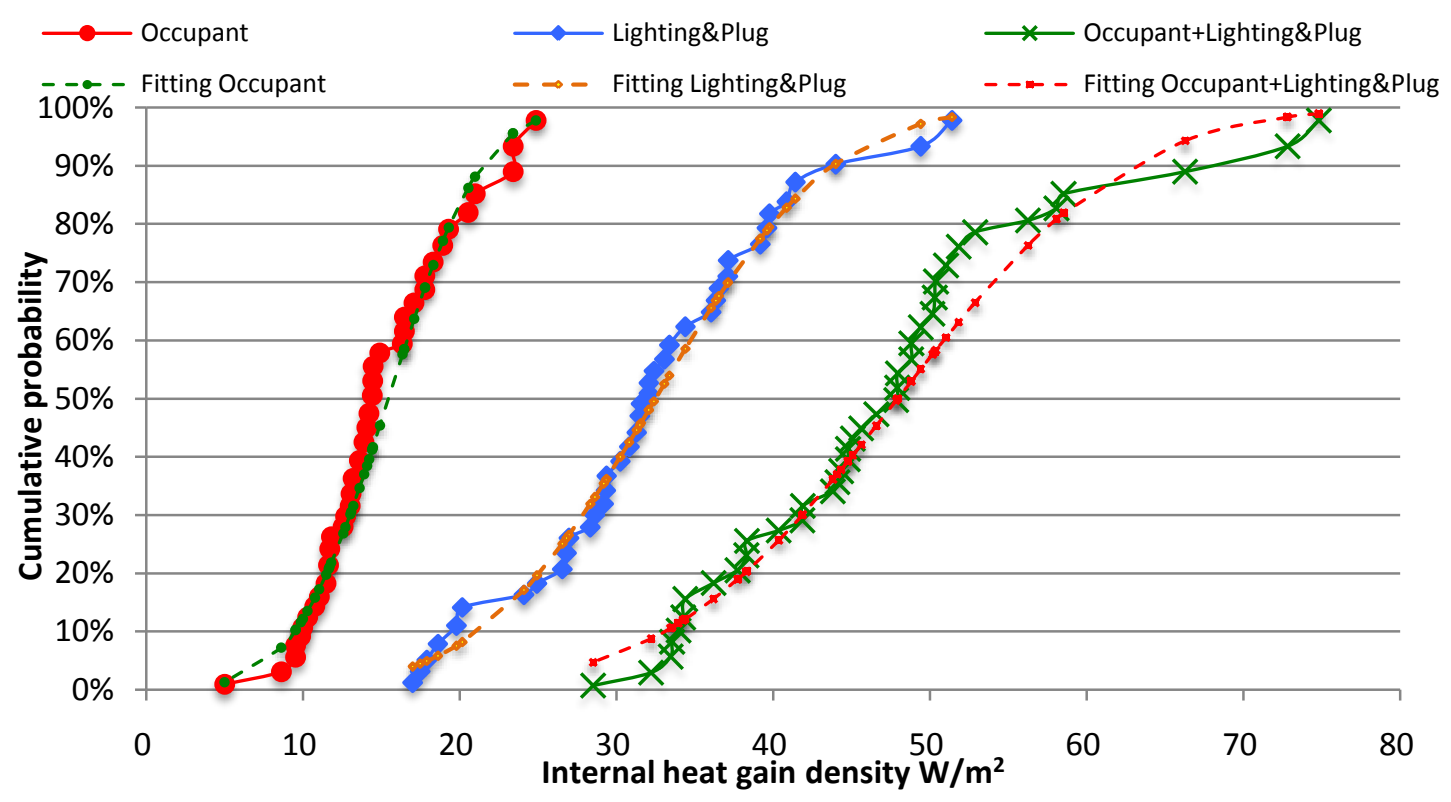

Fig. 5 Cumulative distributions of the survey data and the proposed normal distribution

After the two groups of curves were compared, the observed data and fitting distributions were found to be highly consistent. The coefficients of determination $\left(\mathrm{R}^{2}\right)$ for the distributions of the occupant loads, lighting and plug loads, and total internal gains were 0.986, 0.995, and 0.985 respectively. The results indicated that the densities of internal heat gains can be described by using normal distribution functions.

The expected value $\mu$ is the average level of internal heat gain density for different tenants. The standard deviation $\sigma$ reflects the variation or dispersion degree of the internal heat gain density for different tenants. Combined, the two parameters can thoroughly describe the distribution characteristics from two perspectives: the central tendency and spread of internal heat gains in buildings. Therefore, the normal distribution can describe the spatial distribution characteristics of the internal heat gain density in large-sized office buildings. The expected value and standard deviation are used to describe the spatial average and spatial dispersion degree of the internal heat gain, respectively. The average internal heat gain density increases with the expected value. The spatial dispersion degree of the internal heat gain density increases with the standard deviation. The expected value and standard deviation can be estimated from a large number of investigated cases. In this research, 40 cases provided sufficient data to obtain smooth distribution functions for the internal heat gains.

The floor area that needs to be air-conditioned can influence the parameters and function shape. A larger area leads to a more concentrated distribution function. The following sections explain the changes in distribution functions due to a varying floor area. For instance, chillers are responsible for the whole building, whereas air handling equipment are responsible for part of the building area. Therefore, the distribution functions of chillers and air handling equipment have different standard deviations and curve shapes. In addition, we chose different guaranteed rates to determine the internal heat gain values used to select the equipment. High-rise office buildings may require a high guaranteed rate for the air-conditioning system, maybe even 99\%. General office buildings may require a lower guaranteed rate for the air-conditioning system, such as $95 \%$. 


\subsection{Standardization of the distribution function}

Based on the investigation results, Fig. 5 shows the curve characteristics for the average floor area of $1250 \mathrm{~m}^{2}$. However, the actual floor area varies according to the service areas of different equipment (e.g., air handling equipment and chiller). Therefore, this section describes a method for standardizing the curve characteristics of buildings with floor areas of $1000 \mathrm{~m}^{2}$.

The curve characteristics of an average floor area of $1250 \mathrm{~m}^{2}$ is the sum of the characteristics for every $1 \mathrm{~m}^{2}$ of floor area. For a space with a floor area of $\mathrm{n} \mathrm{m}^{2}, X_{1}{ }^{1}, X_{1}{ }^{2}, X_{1}{ }^{3}, \cdots, X_{1}{ }^{n}$ represent the internal heat gain densities of each space with a floor area of $1 \mathrm{~m}^{2} . X_{n}$ represents the internal heat gain density of the whole space. Then,

$$
X_{n}=\left(X_{1}{ }^{1}+X_{1}{ }^{2}+X_{1}{ }^{3}+\cdots+X_{1}{ }^{n}\right) / n
$$

If $X_{1}{ }^{1}, X_{1}{ }^{2}, X_{1}{ }^{3}, \cdots, X_{1}{ }^{n}$ follow the normal distribution function $N\left(\mu, \sigma^{2}\right)$, then $X_{n}$ obeys $N\left(\mu, \frac{\sigma^{2}}{n}\right)$

In the investigated cases, when the distribution for a floor area of $1250 \mathrm{~m}^{2}$ was $X_{1250} \sim N\left(47.9,11.6^{2}\right)$, then the distribution for a floor area of $1 \mathrm{~m}^{2}$ was $X_{1} \sim N\left(47.9,11.6^{2} \times\right.$ 1250) $\sim N\left(47.9,410.1^{2}\right)$.

In order to standardize the distribution, a floor area of $1000 \mathrm{~m}^{2}$ can be treated as a basic area. The distribution for a floor area of 1000 $\mathrm{m}^{2}$ was $X_{1000} \sim N\left(47.9,11.6^{2} \times 1250 / 1000\right) \sim N\left(47.9,13.0^{2}\right)$. Fig. 6 shows the influence of different floor areas on the distribution characteristics. A larger floor area led to a smaller standard deviation, which corresponded to a more centralized distribution curve.

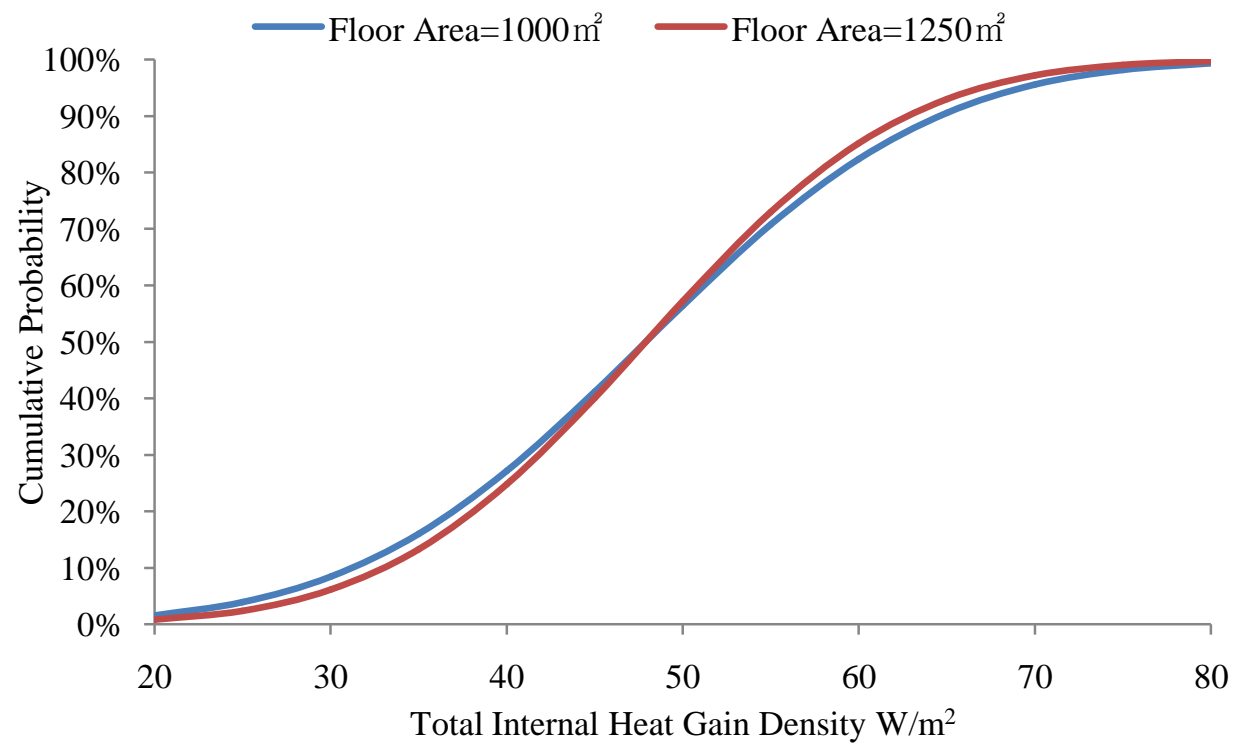

Fig. 6 Standardization of cumulative distributions with different floor areas

\section{Approach to obtain the design internal heat gains}

\subsection{Influence of the spatial distribution characteristics of internal heat gains on the sizing of}

\section{air handling cooling equipment}

As discussed previously, the internal heat gain density is an important parameter for 
calculating the cooling load and equipment capacity. The optimal internal heat gain density is premised on ensuring indoor comfort while avoiding equipment oversizing.

We used different guaranteed rates to select the cooling equipment. The guaranteed rate is the cooling capacity that covers the internal heat gain. Note that the building load is composed of several elements, such as the envelope load, radiation load, outdoor air load, and internal heat gains. The internal heat gain is just one element that influences the overall building load. The internal heat gains and other elements rarely all reach the peak load at the same time. Thus, if the guaranteed rate of the internal heat load is $95 \%$ and the unguaranteed rate is $5 \%$, the overall load guaranteed rate is higher than $95 \%$, which is higher than the original guaranteed rate of the internal heat gains. The guaranteed rate is often determined by designers and owners before the design based on the building grade and other factors.

The expected value $\mu$ and standard deviation $\sigma$ are parameters of the normal distribution function. These parameters are necessary to calculate the density of internal heat gains. Parameters can be derived from a large amount of density data on internal heat gains. In this case, a building with a floor area of $1000 \mathrm{~m}^{2}$ was used as the model. The expected value and standard deviation of the total internal heat gain density are then $\mu=47.9$ and $\sigma=13.0$. Section 4.2 describes the density of internal heat gains with the normal distribution function $N\left(47.9,13.0^{2}\right)$ for a floor area of $1000 \mathrm{~m}^{2}$. When air handling equipment is used to cool a floor area of $1000 \mathrm{~m}^{2}$, the internal heat gain density used to calculate the cooling load and equipment capacity is given by $N\left(47.9,13.0^{2}\right)$. If the air handling equipment controls a different floor area, the distribution function can be expressed by $N\left(47.9,13.0^{2} /\left(\frac{\mathrm{A}}{1000}\right)\right)$, where $A$ is the floor area of building.

Because the distribution is a non-standard normal distribution function, the following steps can be performed to obtain the internal heat gain density value based on the standard normal distribution function:

1) $X$ is the density distribution function of the tenant internal heat gains that obeys the normal distribution function $\sim N\left(\mu, \sigma^{2}\right)$;

2) $X$ is transformed to the standard normal distribution function $U=(X-\mu) / \sigma \sim N(0,1)$;

3) The characteristics of the standard normal distribution function are known and can be checked; for example, the standard normal values for the guaranteed rates of 0.95 and 0.99 are $U_{0.95}=1.64$ and $U_{0.99}=2.33$, respectively;

4) By using the formula $X=\sigma U+\mu$, the internal heat gain density value used to calculate the load and equipment capacity can be obtained.

Therefore, the expected value and standard deviation of the total internal heat gain density are $\mu=47.9$ and $\sigma=13.0$, respectively, in this case. By choosing 0.95 and 0.99 as the guaranteed rates, the internal heat gain density values can be calculated:

$$
\begin{aligned}
& X_{0.95}=\sigma U_{0.95}+\mu=13.0 \times 1.64+47.9=69.2 \\
& X_{0.99}=\sigma U_{0.99}+\mu=13.0 \times 2.33+47.9=78.2
\end{aligned}
$$


However, the floor area that is air-conditioned by one air handling equipment often changes. When the service floor area varies, obtaining information on how the internal heat gain density value would change is useful. Fig. 7 shows the influence of the service floor area on the internal heat gain density. With different floor areas, the standard deviations show significant differences. The standard deviations $\sigma$ for 500, 1000, and $2000 \mathrm{~m}^{2}$ are 18.4, 13.0, and 9.2, respectively. As shown in Fig. 7, a higher guaranteed rate increases the internal heat gain density. As the guaranteed rate approaches $100 \%$, the increase in the internal heat gain density accelerates. At a guaranteed rate of $95 \%$, the internal heat gain density values of 500, 1000, and $2000 \mathrm{~m}^{2}$ are 78.1 , 69.2 , and $63.0 \mathrm{~W} / \mathrm{m}^{2}$, respectively. Compared with the values for $1000 \mathrm{~m}^{2}$, the disparities are $13 \%$ and $-9 \%$. At the same guaranteed rate, a larger service area leads to a more centralized distribution. Hence, the specific value used for selecting air handling equipment for a small area is less than that used to serve a bigger floor area.

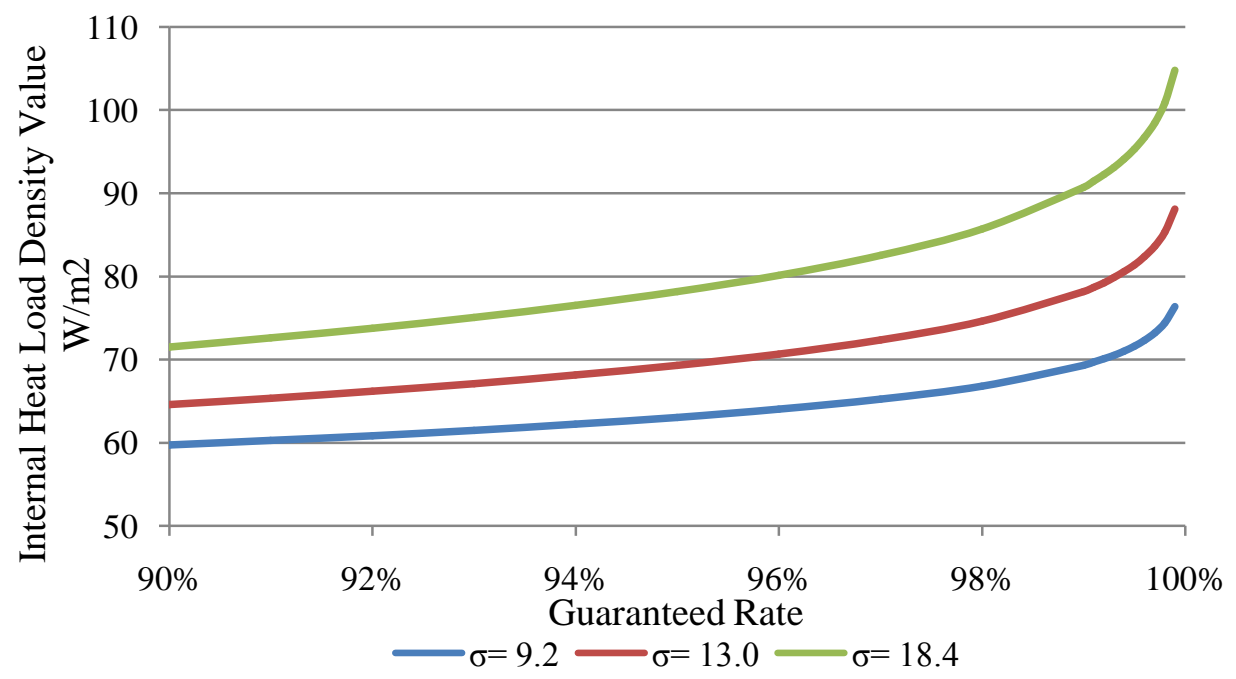

Fig. 7 Influence of the floor area and standard deviation on the internal heat gain density

Therefore, when air handling cooling equipment is being sized, the internal heat gain density value should be determined by considering the floor area and guaranteed rate, especially in office buildings where most of the floors are standard layers. This situation provides favorable conditions for the internal heat gain density when the variation in floor area is considered. The guaranteed rate can be chosen by the engineer according to the different requirements of buildings.

\subsection{Influence of the spatial distribution of internal heat gains on the chiller capacity}

The chiller provides the cooling capacity for the whole building. The distributions of internal heat gains in an office building are different for each room and floor because of the variations in the floor area. Rooms and floors are likely to be rented to different tenants in a large office building. Thus, the characteristics of the whole building are the result of the combined effects of these tenants. The possibility that all tenants are in the same situation of a high internal heat gain density is very low. This means that the distribution characteristics of the whole building are more centralized than one room or one floor. These characteristics lead to different density values for the internal heat gain, which have an apparent influence on the chiller and air handling equipment 
size.

Based on the formula give in section 4.2 , the whole building distribution function can be transformed from a floor area of $1000 \mathrm{~m}^{2}$ to other specific areas. Fig. 8 shows the cumulative distribution functions of the air handling equipment and chiller, and Fig. 9 illustrates the PDF of the air handling equipment and chiller. Fig. 8 and Fig. 9 are based on the assumption that the air handling equipment controls an area of $1000 \mathrm{~m}^{2}$ while the chiller controls an area of $20,000 \mathrm{~m}^{2}$. Because the whole building floor area is much larger than the area of one air handling equipment, the standard deviation is much smaller. The distribution function mainly varies over a small range.

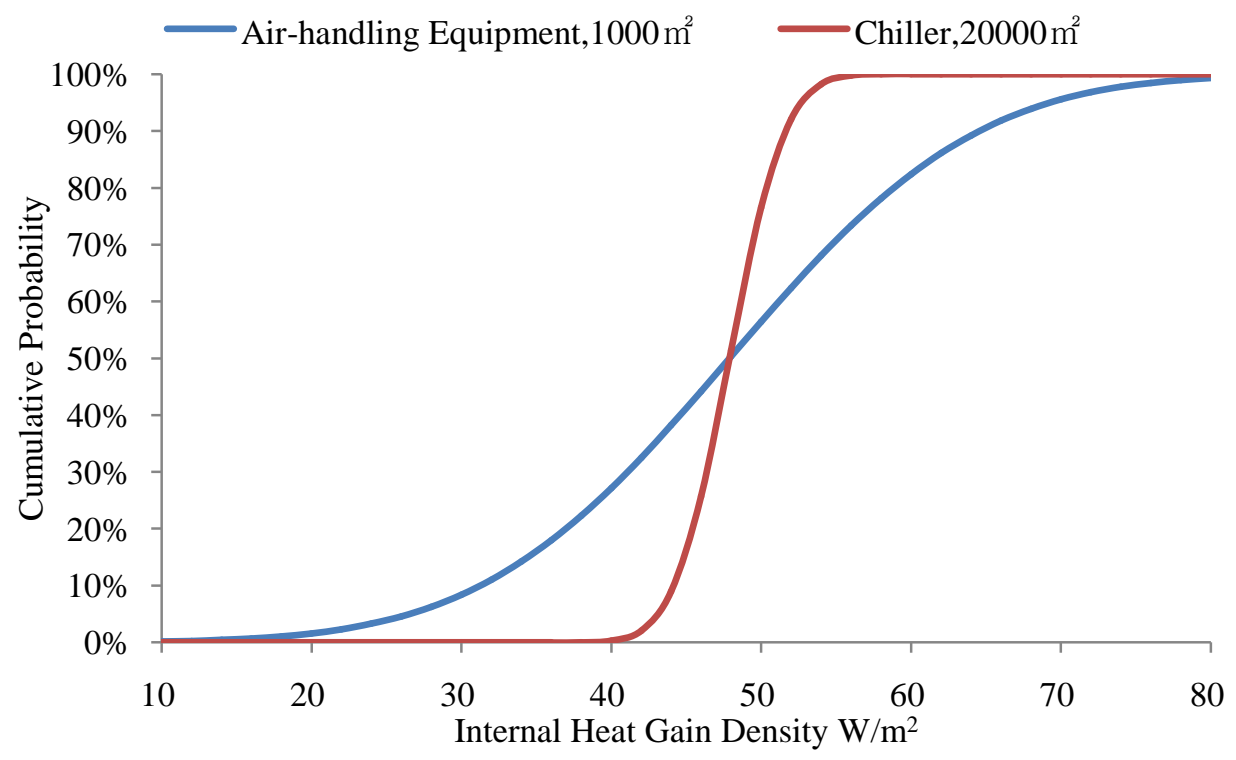

Fig. 8 Cumulative distribution of the air handling equipment and chiller

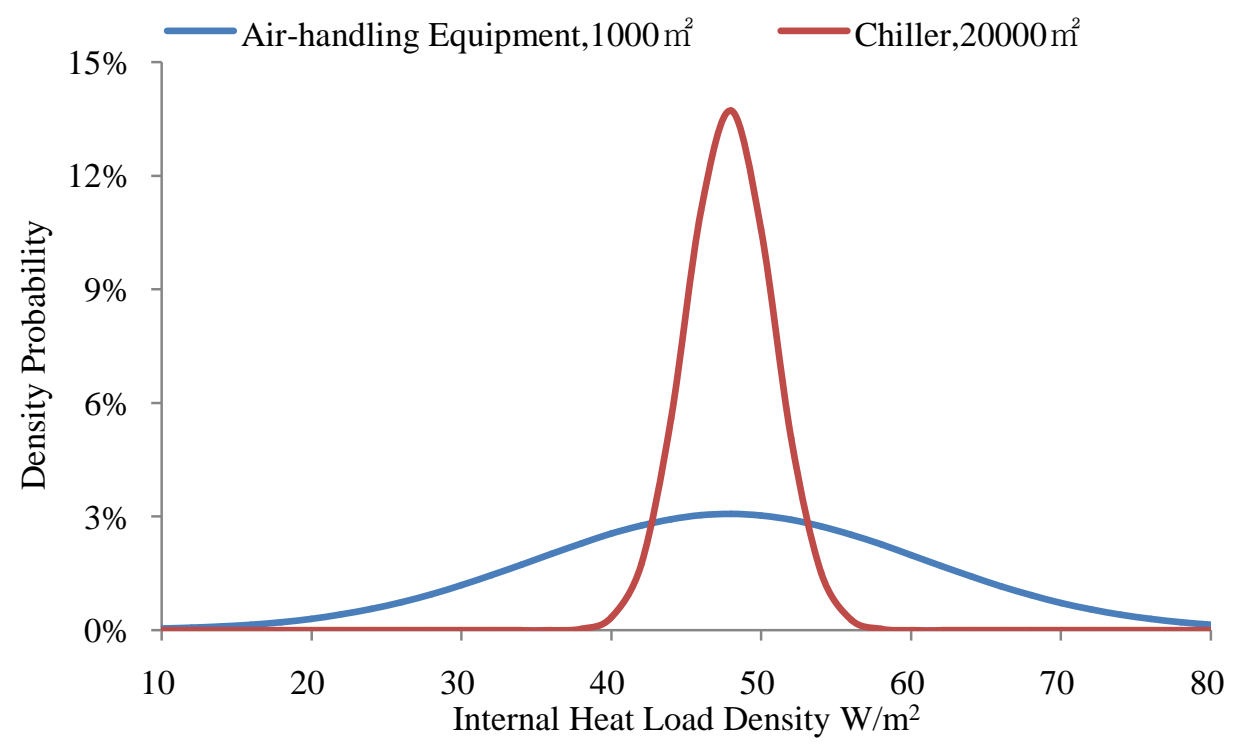

Fig. 9 Density distribution of the air handling equipment and chiller

Because of the gap between the chiller and air handling equipment distribution characteristics, the internal heat gain density values used to calculate the cooling capacity are distinct. Table 3 presents the internal heat gain density values of the chiller and air handling equipment. As the guaranteed rate increases, the gap between the internal heat gains of the chiller and air handling equipment becomes more obvious. The gap is $13.0 \mathrm{~W} / \mathrm{m}^{2}$ at a guaranteed rate of $90 \%$ and 31.2 
$\mathrm{W} / \mathrm{m}^{2}$ at a guaranteed rate of $99.9 \%$. This means that, in a high-rise office building with a high guaranteed rate, the cooling capacity gap between the chiller and air handling equipment is more significant when the spatial distribution is considered.

Table 3 Internal heat gain density values of the chiller and air handling equipment

\begin{tabular}{ccc}
\hline & $\begin{array}{c}\text { Air Handling Equipment Internal } \\
\text { Geat Gain Density of } 1000 \mathrm{~m}^{2}\end{array}$ & $\begin{array}{c}\text { Chiller Internal Heat Gain } \\
\text { Density of } 20,000 \mathrm{~m}^{2} \\
\mathrm{~W} / \mathrm{m}^{2}\end{array}$ \\
\hline $90.0 \%$ & 64.6 & 51.6 \\
$95.0 \%$ & 69.3 & 52.7 \\
$99.0 \%$ & 78.1 & 54.7 \\
$99.9 \%$ & 88.1 & 56.9 \\
\hline
\end{tabular}

With the trend of increasing building scale and number of levels, the building floor area is often beyond $20,000 \mathrm{~m}^{2}$. A larger floor area leads to a more centralized the distribution function. Fig. 10 shows the internal heat gain density of the chiller with a changing floor area for guaranteed rates of 0.95 and 0.99 . When the floor area is less than $20,000 \mathrm{~m}^{2}$, the decrease in the internal heat gain density with increasing floor area accelerates. When the floor area is more than $20,000 \mathrm{~m}^{2}$, the decreasing trend slows down. At higher guaranteed rates, the internal heat gain density increases. The gap between the internal heat gain densities is apparent when the floor area is less than $20,000 \mathrm{~m}^{2}$.

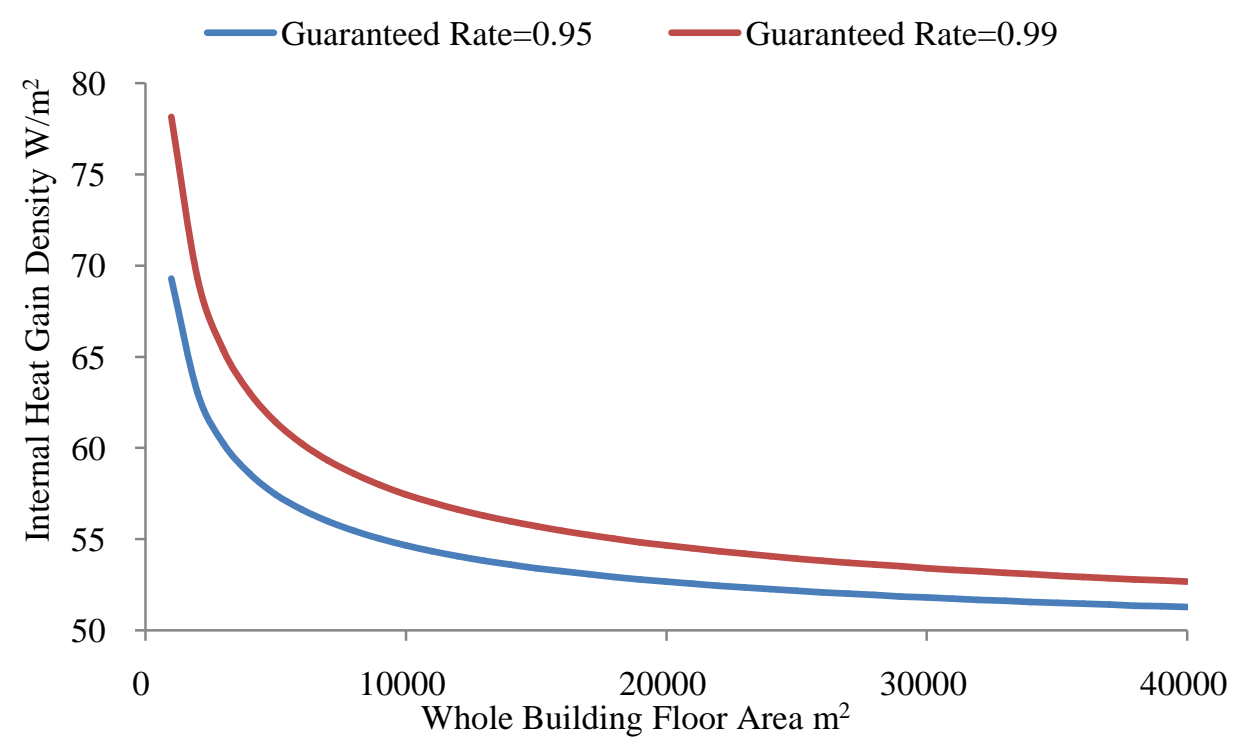

Fig. 10 Internal heat gain density of a chiller with a changing floor area

\subsection{Influence of the spatial distribution of internal heat gains on the air handling heating}

\section{equipment and heat pump sizing}

We earlier discussed how to calculate the internal heat gains for sizing cooling equipment (e.g., AHU and chiller). Here, we consider the sizing of heating equipment. There are obvious differences between the cooling and heating load calculations. Internal heat gains increase the cooling load but decrease the heating load. Therefore, in order to meet the comfort requirements of the occupants, Researchers use a larger internal heat gain value to size cooling equipment but a 
smaller or zero value for sizing heating equipment in most HVAC system designs. In this study, we chose internal heat gain values according to the distribution function and guaranteed rate. A larger design internal heat gain increases the guaranteed rate for cooling equipment sizing. In contrast, a smaller design internal heat gain decreases the guaranteed rate for cooling equipment sizing. Table presents the internal heat gain density values for sizing heating and cooling equipment.

Table 4 Internal heat gain density for sizing heating and cooling equipment

\begin{tabular}{|c|c|c|c|c|}
\hline $\begin{array}{c}\text { Guaranteed } \\
\text { Rate } \\
\%\end{array}$ & $\begin{array}{c}\text { Air Handling Cooling } \\
\text { Equipment Internal Heat } \\
\text { Gain Density of } 1000 \mathrm{~m}^{2} \\
\mathrm{~W} / \mathrm{m}^{2}\end{array}$ & $\begin{array}{c}\text { Chiller Internal Heat Gain } \\
\text { Density of } 20,000 \mathrm{~m}^{2} \\
\mathrm{~W} / \mathrm{m}^{2}\end{array}$ & $\begin{array}{c}\text { Air Handling Heating } \\
\text { Equipment Internal Heat } \\
\text { Gain Density of } 1000 \mathrm{~m}^{2} \\
\mathrm{~W} / \mathrm{m}^{2}\end{array}$ & $\begin{array}{c}\text { Heat Pump Internal Heat } \\
\text { Gain Density of } 20,000 \mathrm{~m}^{2} \\
\mathrm{~W} / \mathrm{m}^{2}\end{array}$ \\
\hline 90.0 & 64.6 & 51.6 & 31.2 & 44.2 \\
\hline 95.0 & 69.3 & 52.7 & 26.5 & 43.1 \\
\hline 99.0 & 78.1 & 54.7 & 17.7 & 41.1 \\
\hline 99.9 & 88.1 & 56.9 & 7.7 & 38.9 \\
\hline
\end{tabular}

\section{Case Study}

Based on its spatial distribution characteristics for the internal heat gain density, building D was used as an example to demonstrate the accuracy of the proposed method. Building D is located in Hong Kong, where there is no need to supply heat. Building D has been used since 2008 and reached full occupancy by the end of 2009. Building D is mainly used as rented offices with 67 floors. Each standard office floor has an area of $2380 \mathrm{~m}^{2}$, and the gross floor area is 161,500 $\mathrm{m}^{2}$.

By considering the spatial characteristics of internal heat gains, the chiller capacity can be significantly reduced while the cooling demand is ensured. Fig. 11 compares the chiller capacity, calculated cooling capacity, and actual peak cooling load. The chiller capacity is the sum of the individual capacities of chillers installed at building D, which was $32,673 \mathrm{~kW}$. Note that the total cooling load is affected by factors in four categories, as introduced in ASHRAE Handbook-Fundamentals: external (envelope), internal (occupant, lighting, and plug loads/appliances), infiltration (air leakage), and system (outdoor air, duct leakage, fan and pump). The envelope load represents the load caused by building envelope heat transfer and solar radiation heat gains. The internal heat load is the internal heat gains from occupants, lighting, and plug loads/appliances. The air conditioning equipment load refers to the load brought by heat from fans and pumps in the HVAC systems. This cannot be ignored because the building was served by all air systems in the case study, and the temperature rise of the supply air caused by fans and of the supply water by the pumps was significant. The calculated building cooling load obtained with the traditional original method was $25,791 \mathrm{~kW}$. The article method used the new internal heat gain, which considered the spatial characteristics; other cooling loads, such as the outdoor fresh air load and envelope load, were the same as those used in the original method. The result with the proposed method was $18,914 \mathrm{~kW}$. The actual peak cooling load was the peak of the measured cooling load based on the temperature and flow. For building D, which was measured hourly from 2009 to 2011 , the actual peak cooling load was $18,534 \mathrm{~kW}$. The chiller capacity was oversized by 
43\% compared to the actual peak cooling load. Because the spatial distribution characteristics were considered, the building cooling load calculated with the proposed method was closer to the actual peak cooling load. In contrast, the calculated building cooling load with the traditional method was 39\% higher than the actual peak cooling load. Thus, the calculated cooling load with the proposed method was closer to the actual cooling demand. This confirms that the spatial distribution should be considered when the cooling load in office buildings is calculated.

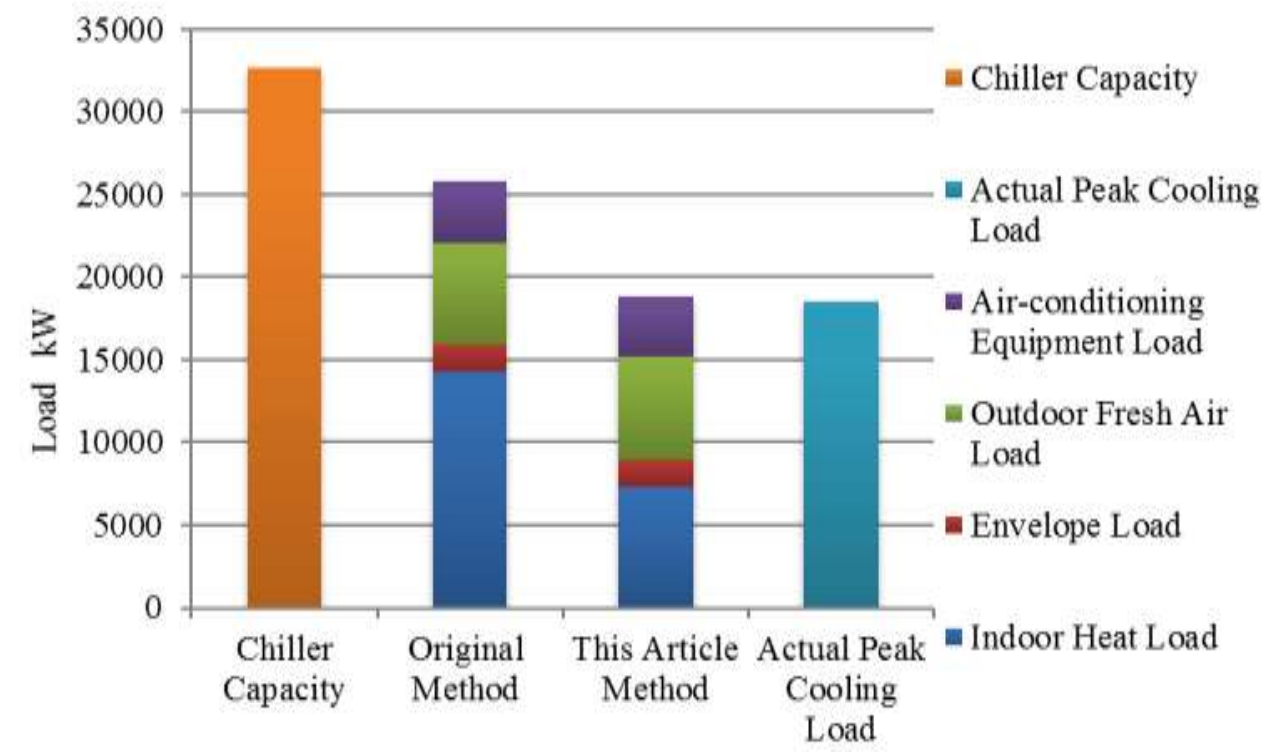

Fig. 11 Comparison of the installed chiller capacity, calculated cooling capacity, and actual peak cooling load

In building $\mathrm{D}$, one air handling equipment controls a floor area of $1600 \mathrm{~m}^{2}$, and there are 63 air-conditioned office floors. The total building office floor area is $100,800 \mathrm{~m}^{2}$. Table 5 presents the internal heat gain densities using the different methods.

Table 5 Internal heat gain density of different methods

\begin{tabular}{clc}
\hline & Directions & Internal Heat Gain Density \\
& & $\mathrm{W} / \mathrm{m}^{2}$ \\
\hline Original Method & Not considering spatial distribution characteristics & 97.4 \\
& Maximum of investigated cased & 50.0 \\
This Article Method & Considering spatial distribution characteristics & \\
& Used for chiller under 95\% guaranteed rate & \\
\hline
\end{tabular}

\section{Discussion}

Because HVAC equipment is sized in the early design stages, measurements are not available at that time. Therefore, the article method should be carried out on some typical existing buildings with measurements to estimate the distribution of internal heat gains by developers of building design standards, engineers of real estate companies, etc.

Note that the limited field survey data of internal heat gains used in this study are not adequate for providing general guidance on sizing AHUs and chillers. In addition, because of the limited measurements, the current survey results treated lighting and plug loads together. However, 
these should be considered separately for both design sizing calculations and energy simulation. With the development and adoption of sub-metering technology in large buildings, in the future we can provide a table of separate design internal heat gains-broken down into occupants, lighting, and plug loads - at different guaranteed rates from a large-scale survey or monitoring with the article approach. This will improve HVAC equipment sizing and lead to more efficient operation and lower energy use in buildings.

\section{Conclusion}

In large office buildings with central air-conditioning systems, the internal heat gain density varies significantly among tenant spaces. However, traditional practice uses a uniform internal heat gain density to calculate the peak cooling loads for determining the capacities of chiller plants and air handling equipment; the spatial distribution characteristics of internal heat gains are not considered. In order to guarantee the capacity of air handling equipment, a higher internal heat gain density is often used, which results in an oversized chiller plant.

In this study, we investigated the internal heat gains from occupants, lighting, and plug loads of 46 tenants in seven office buildings in Hong Kong. We found that the internal heat gains vary in a normal distribution and that there are large gaps (19\%-45\%) between the selected chiller capacity and actual peak cooling load. Therefore, we propose a method for describing the spatial distribution characteristics of internal heat gains by using a normal distribution function, which can be used together with a guaranteed rate to determine the internal heat gains for peak load calculations and equipment sizing. Because the distribution characteristics of one tenant are more dispersed while the distribution characteristics of the whole building are more concentrated, the internal heat gain density values used to calculate the chiller capacity are smaller than those used to calculate the air handling equipment capacity. This means that HVAC designers should compute the room cooling loads and building cooling loads separately by using different internal heat gain densities. The case study of a large office building was used to demonstrate the proposed probabilistic approach. The results showed that the calculated building cooling load for chiller sizing with the proposed method was close to the actual peak cooling load, while the calculated load with the traditional method was $39 \%$ higher.

The proposed approach of considering the spatial characteristics of internal heat gains and different guaranteed rates can effectively address the chiller oversizing issue, reduce the initial costs, save chiller plant space, and improve the operating efficiency while meeting occupant comfort requirements.

\section{Acknowledgement}

This work was supported by Swire Properties which also provided the investigation data, and Innovative Research Groups of the National Science Foundation of China, China (Grant number 51521005). This work was also supported by the Assistant Secretary for Energy Efficiency and Renewable Energy, the U.S. Department of Energy (Grant number DE-AC02-05CH11231).

\section{References}

[1] W L Leea, F W H Yika, P Jones, et al. Energy saving by realistic design data for commercial buildings in Hong Kong. Applied Energy, 2001, 70: 59-75

[2] Tianzhen Hong, S K Chou, T Y Bong. A design day for building load and energy estimation. Building and 
Environment, 1999, 34: 469-477

[3] PC Thomas, Steven Moller. HVAC System Size: Getting it Right: Right-sizing HVAC Systems in Commercial Buildings. Crc for Construction Innovation, 2007.

[4] Barry Crozier. Enhancing the performance of oversized plant. Application Guide AG 1/2000, BSRIA, 2000.

[5] Shiming D. Sizing Replacement Chiller Plants. Ashrae Journal, 2002, 44(6):págs. 47-49.

[6] Philip C H Yu, W K Chow. Sizing of air-conditioning plant for commercial buildings in Hong Kong. Applied Energy, 2009, 66: 91-103

[7] Gavin Dunn, Ian Knight. Small power equipment loads in UK office environments. Energy and Buildings, 3005, 37: 87-91

[8] L. Moorefield, B. Frazer, P. Bendt. Office Plug Load Field Monitoring Report. Ecos Consulting, California, 2011

[9] Domínguez-Muñoz F, Cejudo-López J M, Carrillo-Andrés A. Uncertainty in peak cooling load calculations. Energy \& Buildings, 2010, 42(7):1010-1018.

[10] Stephen T H Lao MSC. An Evaluation of the Rules of Thumb for Estimating Cooling Load for Office Buildings. Hkie Transactions, 2001, 8(3):58-59.

[11] Macdonald I A. Quantifying the Effects of Uncertainty in Building Simulation. University of Strathclyde, 2002.

[12] K. Sun, T. Hong, S.C. Taylor-Lange, M.A. Piette, A pattern-based automated approach to building energy model calibration, Appl. Energy. 165 (2016) 214-224. doi:10.1016/j.apenergy.2015.12.026.

[13] Tian W. A review of sensitivity analysis methods in building energy analysis. Renewable and Sustainable Energy Reviews, 2013, 20: 411-419.

[14] I.A. Macdonald, Quantifying the effects of uncertainty in building simulation. PhD thesis, ESRU, University of Strathclyde, 2002.

[15] Lomas K J, Eppel H. Sensitivity analysis techniques for building thermal simulation programs. Energy and buildings, 1992, 19(1): 21-44.

[16] J.M. Fuerbringer, Sensitivity of models and measurements in the airflow in buildings with the aid of experimental plans. Sensibilite de Modeles et de mesures en aeraulique de batiment a l'aide de plans d'experiences. Switzerland, Lausanne, Ecole Polytechnique Federale de Lausanne, 1994.

[17] Tian W, Wilde P D. Uncertainty and sensitivity analysis of building performance using probabilistic climate projections: A UK case study. Automation in Construction, 2011, 20(8):1096-1109.

[18] Macdonald I, Strachan P. Practical application of uncertainty analysis. Energy \& Buildings, 2001, 33(33):219-227.

[19] Wit S D, Augenbroe G. Analysis of uncertainty in building design evaluations and its implications. Energy \& Buildings, 2002, 34(9):951-958.

[20] Hopfe C J, Hensen J L M. Uncertainty analysis in building performance simulation for design support. Energy and Buildings, 2011, 43(10): 2798-2805.

[21] Spitz C, Mora L, Wurtz E, et al. Practical application of uncertainty analysis and sensitivity analysis on an experimental house. Energy and Buildings, 2012, 55: 459-470.

[22] Wang C, Yan D, Jiang Y. A novel approach for building occupancy simulation. Building Simulation, 2011, 4(2):149-167. 
[23] Feng X, Yan D, Hong T. Simulation of occupancy in buildings. Energy \& Buildings, 2014, 87:348-359.

[24] Hong T, Taylor-Lange S C, D'Oca S, et al. Advances in Research and Applications of Energy-Related Occupant Behavior in Buildings. Energy \& Buildings, 2015.

[25] Yan D, O’Brien W, Hong T, et al. Occupant behavior modeling for building performance simulation: Current state and future challenges. Energy \& Buildings, 2015, 107:264-278.

[26] Yinxin Zhu, Yi Jiang. Annual Twin Load Curves Analysis for HVAC system design. HV\&AC, 1998, 28(4): $43-46$

[27] Siriwarin Petcharat, Supachart Chungpaibulpatana, Pattana Rakkwamsuk. Assessment of potential energy saving using cluster analysis A case study of lighting systems in buildings. Energy and Buildings, 2012, 52: $145-152$

[28] Yaoqing Lu. Practical HVAC design handbook (Second edition). Beijing: China Building Industry Press, 2008: $1547-1561$

[29] Zhun (Jerry) Yu, Fariborz Haghighat, Benjamin C M, et al. A novel methodology for knowledge discovery through mining associations between building operational data. Energy and Buildings, 2012, 47: 430-440

[30] D'Oca, S. and Hong, T. A data-mining approach to discover patterns of window opening and closing behavior in offices. Building and Environment, 2014, 82, pp.726-739.

[31] Yun, G.Y., Kim, H. and Kim, J.T. Effects of occupancy and lighting use patterns on lighting energy consumption. Energy and Buildings, 2012, 46, pp.152-158.

[32] Sun, K., Yan, D., Hong, T. and Guo, S. Stochastic modeling of overtime occupancy and its application in building energy simulation and calibration. Building and Environment, 2014, 79, pp.1-12.

[33] Handbook, American Society of Heating, Refrigerating and Air Conditioning Engineers (ASHRAE). Fundamentals, Chapter18, 2013, Atlanta.

[34] Abushakra, B., J.S. Haberl, and D.E. Claridge. Overview of literature on diversity factors and schedules for energy and cooling load calculations (1093-RP). 2004. ASHRAE Transactions 110(1):164-176.

[35] Claridge, D.E., B. Abushakra, J.S. Haberl, and A. Sreshthaputra. Electricity diversity profiles for energy simulation of office buildings (RP-1093). 2004. ASHRAE Transactions 110(1):365-377.

[36] Nagai, T. and INagata, A. Probabilistic approach to determination of internal heat gains in office, building for peak load calculations. In Proceedings of BS 2013 13th Conference of the International Building Performance Simulation Association, pp. 2444-2450. 2013. 